\title{
Do Trained Practice Nurses Apply Motivational Interviewing Techniques in Primary Care Consultations?
}

\author{
Janneke Noordman ${ }^{\mathrm{a}, \mathrm{f}}$, Inge van der Lee ${ }^{\mathrm{a}}$, Mark Nielen ${ }^{\mathrm{a}}$, Hans Vlek ${ }^{\mathrm{b}}$, \\ Trudy van der Weijden ${ }^{c}$, Sandra van Dulmen ${ }^{\text {a d, e }}$
}

\begin{abstract}
Background: Reducing the prevalence of unhealthy lifestyle behaviour could positively influence health. Motivational interviewing (MI) is used to promote change in unhealthy lifestyle behaviour as part of primary or secondary prevention. Whether MI is actually applied as taught is unknown. Practice nurses' application of motivational interviewing in real-life primary care consultations was examined. Furthermore, we explored if (and to what extent) practice nurses adjust their motivational interviewing skills to primary versus secondary prevention.
\end{abstract}

Methods: Thirteen Dutch practice nurses, from four general practices, trained in motivational interviewing participated, 117 adult patients visiting the practice nurse participated, 117 practice nursepatient consultations between June and December 2010 were videotaped. Motivational interview skills were rated by two observers using the Behaviour Change Counselling Index (BECCI). Data were analyzed using multilevel regression.

Results: Practice nurses use motivational interviewing techniques to some extent. Substantial variation was found between motivational interviewing items. No significant differences in the use of

Manuscript accepted for publication September 14, 2012

${ }^{a}$ NIVEL, Netherlands Institute for Health Services Research, PO Box 1568, 3500 BN Utrecht, The Netherlands

brimary Care Centre Tiel (Eerstelijns Centrum Tiel), Dodewaardlaan 9, 4006 EA Tiel, The Netherlands

${ }^{\mathrm{c}}$ Maastricht University, School for Public Health and Primary Care (CAPHRI), Department of General Practice, P.O. Box 616, 6200 MD Maastricht, The Netherlands

${ }^{\mathrm{d}}$ Radboud University Nijmegen Medical Center, Department of Primary and Community Care, Geert Grooteplein Noord 21, 6500 HB Nijmegen, The Netherlands

${ }^{\mathrm{e}}$ Department of Health Science, Buskerud University College, Drammen, Norway

${ }^{\mathrm{f}}$ Corresponding author: Janneke Noordman, NIVEL, Netherlands Institute for Health Services Research, PO Box 1568, 3500 BN

Utrecht, The Netherlands. Email: j.noordman@nivel.nl

doi: http://dx.doi.org/10.4021/jocmr1120w motivational interviewing between primary and secondary prevention was found.

Conclusions: Motivational interviewing skills are not easily applicable in routine practice. Health care providers who want to acquire motivational interview skills should follow booster sessions after the first training. The training could be strengthened by video-feedback and feedback based on participating observation. A possible explanation for the lack of differences between the two types of prevention consultations may be the gain to help patients in primary consultations by preventing complications equals the necessity to help the disease from aggravating in secondary prevention.

Keywords: Communication; Life style; Nurses; Prevention; Primary health care

\section{Introduction}

The World Health Organization advocates the integration of strategies to prevent and manage lifestyle-related chronic conditions in primary health care [1]. Primary health care is a suitable context to identify and address behavioral risk factors [2-4] since utilisation by the general population is high $[5,6]$. Furthermore, interventions aimed at behavioral change often require regular health care contacts [4]. Even though the community added value of primary care preventive activities is generally accepted and broadly advocated, the quality of the actual delivery process during everyday healthcare visits is usually taken for granted, and implementation checks are scarce.

The majority of preventive activities in primary care are delivered by a physician or general practitioner (GP). Generally, GPs make the initial diagnosis, initiate the treatment and facilitate overall continuity of care [7]. Yet, discussing lifestyle and referring to programmes promoting lifestyle can be well performed by a practice nurse (PN) [8-10]. Previous research shows that PNs monitor patients with chronic conditions such as type 2 diabetes [11], provide patients with lifestyle advice and guide them during smoking cessation and weight reduction [12]. The level of professional autono- 
my of nurses varies both within and across countries, but is generally high [13].

Due to GP's lack of time, PNs might be even more suitable for promoting healthy lifestyles than GPs [14, 15]. As PNs spend more time on counseling patients than GPs [16, 17], they may be more oriented towards counseling and other behavioral techniques of importance for the prevention of lifestyle-related chronic conditions.

In the USA, the UK, and beyond, promising results have been reported in changing an unhealthy lifestyle using motivational interviewing (MI) techniques [18-20]. MI is a patient-centered directive approach to enhance intrinsic motivation to behavioral change by helping patients explore and resolve ambivalence between desired behavior and actual behavior $[21,22]$. It focuses on what patients can do to improve their health, as opposed to health care providers telling them what to do. MI has shown to produce positive health behavior change and maintenance [23]. However, there are other behavior change approaches that show similar positive health outcomes [24, 25].

Previous research into MI has focused predominantly on determining whether or not MI is more effective for changing behavior than other interventions [6, 26, 27]. Little is, however, known about the actual use of MI techniques in everyday consultations in general or by PNs specifically [2830].

The aim of the present study is to assess whether PNs apply MI techniques in consultations and if (and to what extent) they adjust their MI skills to primary or secondary prevention of lifestyle-related diseases. A primary prevention consultation aims to prevent the development of a chronic disease such as heart and vascular disease, type 2 Diabetes Mellitus and Chronic Obstructive Pulmonary Disease (COPD), and therefore focuses mainly on avoiding health risks. Secondary prevention consultations focus on people already affected by a chronic disease and attempt to enhance the patient's autonomy, minimize the consequences of the disease and prevent the disease from aggravating. It may be important to distinguish between these two types of prevention consultations as they may require different communication strategies; in primary prevention, PNs may need more time and effort to motivate the patient compared to secondary prevention which may also be reflected in longer visits.

\section{Materials and Methods}

The study has an observational design; real-life consultations between PNs and patients within primary care were observed.

\section{Participants}

Thirteen PNs from four practices trained in MI participated.
All PNs from three practices were approached by contacting the GPs of these practices, who (except for one practice) participated in an earlier study [31]. GPs from one other practice (health care center) contacted us for participation of all of their PNs. PN's prior MI training varied between $1 / 2$ day to six half days. On average PNs had four years of working experience (SD: 2.47, range: 9 months - 9 years and 11 months).

Adult patients scheduled for an appointment with the PN between June and December 2010 were eligible for inclusion. We included approximately ten patients per PN.

\section{Procedure}

Consecutive consultations were videoed using an unmanned digital camera located unobtrusively in the PN's consulting room for one or two random days. The aim was to record ten routine consultations per PN. All the participating PNs provided care to a mixed group of patients e.g. with type 2 diabetes, COPD (secondary prevention), or high risk patients (primary prevention) with e.g. hypertension, counseling on smoking. Discussing patient's lifestyle behavior was a potential component of the consultations, which a $\mathrm{PN}$ or patient could bring up.

Patients were approached by a researcher in the waiting room. They were asked to give written informed consent and to complete a short questionnaire about sociodemographics and lifestyle behaviors (smoking, alcohol use and physical activity).

PNs also gave written informed consent before the video-recording of the consultations and completed a short questionnaire after each consultation about the perceived complaints and diseases of patients. PNs were aware that the study focused on their application of MI skills. Patients were told that analyses would focus on communication skills of PNs in general. Participants could withdraw their consent at any time; no one did.

This study was performed according to Dutch privacy legislation. The privacy regulation was approved by the Dutch Data Protection Authority. According to Dutch legislation, approval by a medical ethics committee was not required for this observational study.

\section{Observations and reliability}

The videotaped consultations were rated by two observers independently. For each consultation the application of MI was coded, using the Behaviour Change Counselling Index (BECCI) checklist $[32,33]$. The BECCI contains eleven, five-point Likert-scaled items related to the practitioners' behaviors and MI techniques, ranging from 'not at all' to 'a great extent' (see Appendix 1). These items are subdivided into four domains: agenda setting and permission seeking (two items, Cronbach's $\alpha=0.61$ ); the why and how of 
Table 1. Baseline Characteristics of the Patients in Both Groups

\begin{tabular}{|c|c|c|c|}
\hline & $\begin{array}{l}\text { Primary prevention } \\
\mathbf{n}=\mathbf{3 9}\end{array}$ & $\begin{array}{l}\text { Secondary } \\
\text { prevention } n=78\end{array}$ & P-value \\
\hline Mean age in years (SD; range) & $\begin{array}{l}64.2 \quad(12.1 ; \quad \text { range: } \\
38.0-84.6)\end{array}$ & $\begin{array}{l}64.5 \text { (11.9; range: } 29.4 \text { - } \\
86.2)\end{array}$ & 0.90 \\
\hline Men $(\%)$ & 43.6 & 47.4 & 0.69 \\
\hline \multicolumn{4}{|l|}{ Educational level (\%) } \\
\hline low & 22.2 & 36.5 & 0.16 \\
\hline middle & 69.4 & 50.0 & \\
\hline high & 8.3 & 13.5 & \\
\hline Married/living together $(\%)$ & 83.3 & 71.4 & 0.17 \\
\hline Dutch ethnicity $(\%)$ & 89.7 & 84.2 & 0.42 \\
\hline Smoking; daily/now and then (\%) & 26.3 & 28.4 & 0.82 \\
\hline Alcohol use; daily/now and then (\%) & $76.3^{*}$ & $52.7^{*}$ & 0.02 \\
\hline Meets recommended physical exercise (\%) & 61.1 & 56.2 & 0.62 \\
\hline
\end{tabular}

* Significant difference between primary prevention and secondary prevention, $X^{2}$ test, $(P<0.05)$.

change in behavior (five items, $\alpha=0.70$ ); the whole consultation (three items, $\alpha=0.69$ ); and talk about targets (one item).

Additionally, as part of BECCI, PNs' speaking time is assessed with a separate item. In line with MI, a practitioner is expected to talk no more than $50 \%$ of the consultation time. Therefore, speaking time is divided into 'consultation with PNs' speaking time half of the time or less' versus 'more than half of the time'. In previous research, BECCI has demonstrated acceptable levels of reliability, validity and sensitivity to detect change [33-35]. To assess interrater reliability, 21 consultations were rated by both observers, resulting in a sufficiently high average Kappa score [36] of 0.81 (range $0.72-1.00$ ).

\section{Statistical analysis}

First, characteristics of the patients in the two prevention groups were calculated. Differences between the groups were tested using independent t-test for continuous variables and chi-square test for dichotomous and categorical variables. Second, the average scores for the separate BECCIdomains, the BECCI total, speaking time and consultation length are compared between the two groups with an independent t-test and a chi-square test. Third, multilevel linear regression analyses with a random intercept were performed to determine the association between the four domain scores of the BECCI, BECCI total score and consultation length (dependent variables) with the types of prevention consultations (model 1). This means that we created a separated model for every dependent variable with the type of prevention consultation. The multilevel technique was used to correct for clustering of patients within PNs [37]. Thereafter, model 1 (for every dependent variable) was corrected for confounding in two steps. Firstly, patients' social demographic characteristics - age, gender, marital status, educational background and ethnicity - were added to the model (model 2). Secondly, patients risk factors - smoking, alcohol use and physical activity - were added to model 2 (model 3). Interaction terms were added to model 3 to test for potential effect modification.

Finally, the association between the speaking time of the $\mathrm{PN}$ and the types of prevention consultations was analyzed with multilevel logistic regression analyses with a random intercept using the second order PQL method (model 1). Due to the low number of patients in the primary prevention 


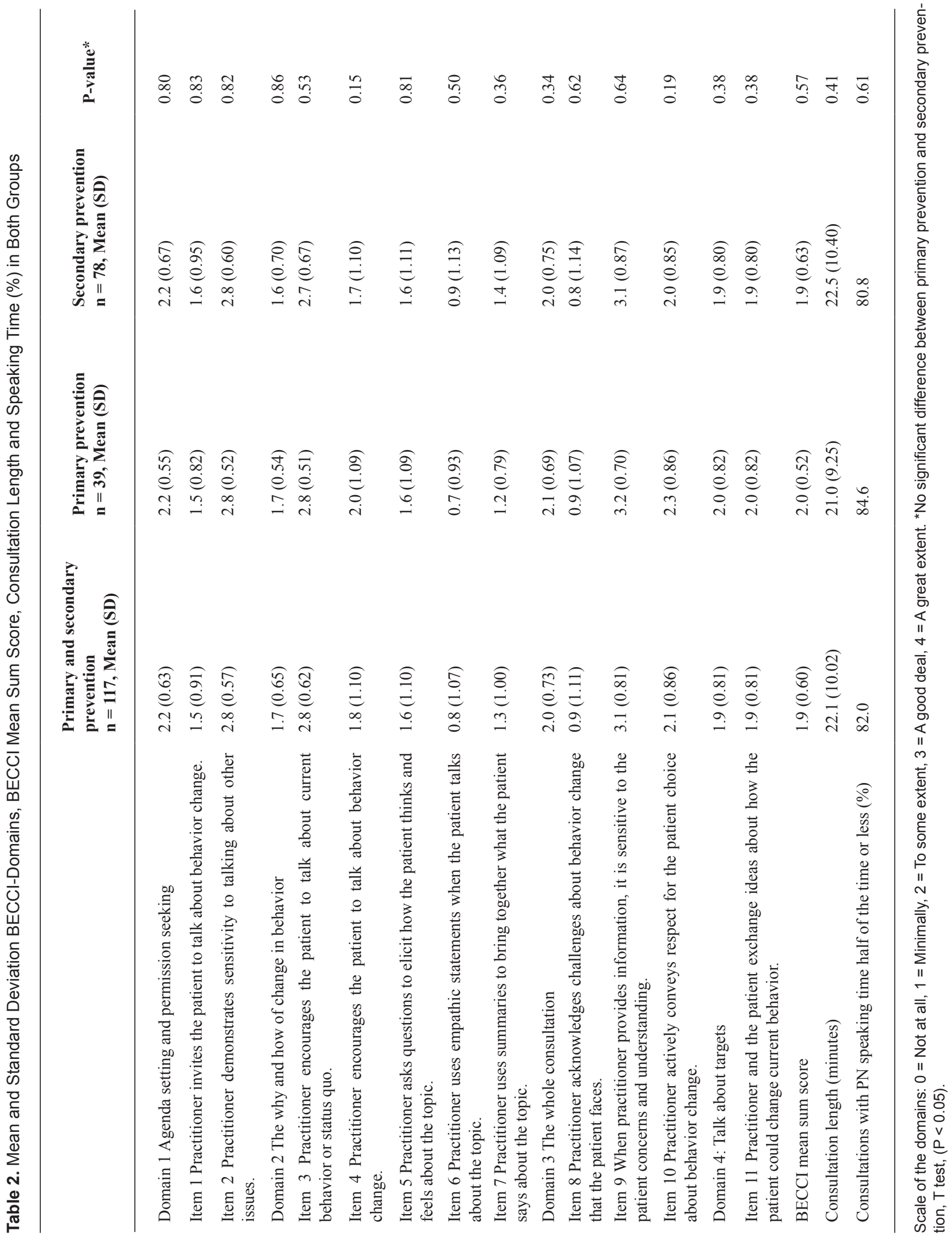


group $(\mathrm{n}=39)$, this association could only be corrected for age and gender (model 2). The analyses were performed in Stata 11 (www.stata.com) and MLwiN [38].

\section{Results}

\section{Subjects}

A total of 117 consultations were analyzed; 78 were secondary prevention consultations, of which 58 with patients with type 2 diabetes, and 39 were aimed at primary prevention, e.g. hypertension $(n=18)$, high cholesterol $(n=2)$, impaired glucose tolerance $(n=4)$ or combinations of these. Patient's non-response rate was $6 \%$. We excluded four patients receiving Cardiovascular Risk Management (CVRM) because CVRM-consultation can be classified as a primary as well as a secondary prevention consultation at the same time. The characteristics of the two groups are depicted in Table 1.

\section{The application of MI techniques}

Table 2 shows the average scores on the separate BECCI-domains, BECCI mean sum score, speaking time and consultation length. PNs scored highest in Domain 1, with an average score of 2.2. The underlying item about inviting the patient to talk about behavior change had a mean score of 1.5 , the item 'demonstrating sensitivity to talking about other issues' had a mean score of 2.8. The participating PNs tend to give patients a choice in what to talk about, but they scored low on asking patients about their willingness to talk about their behavior.

Domain 2 showed the lowest average score of 1.7. The underlying item about encouraging the patient to talk about current behavior or status quo had an average score of 2.8 . This suggests that PNs regularly ask open questions and/or use empathic listening statements, but fail to meet the other four items belonging to domain 2 (notably: the lack of using empathic statements when the patient talks about the topic averaged 0.8).

Domain 3 had a mean score of 2.0. The average score of 3.1 for the item about providing information which is sensitive to patient's concerns and understanding is high compared to the item 'acknowledges challenges about behavior change that the patient faces' (mean 0.9). PNs try to understand what the patient knows and wants to know, but focus insufficiently on the personal strengths of the patient while facing behavioral changes.

Domain 4 consists of one item 'exchanging ideas about how the patient could change current behavior' and has an average score of 1.9 .

In line with BECCI, practitioners should talk no more than $50 \%$ of the time. In $18 \%$ of the consultations PNs talked more than $50 \%$ of the time.

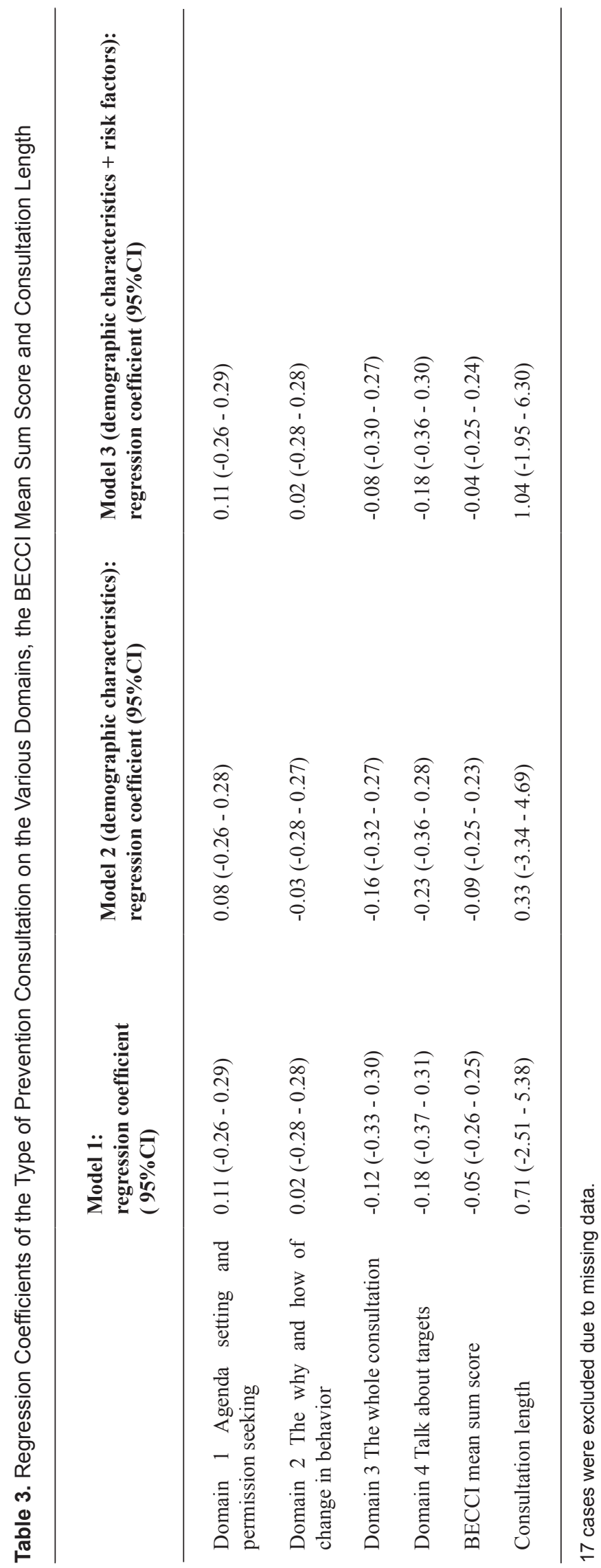


The duration of consultations varied between $4.6 \mathrm{~min}$ utes and 46.7 minutes, with a mean duration of 22.5 minutes $(\mathrm{sd}=10.02)$. There is a significant relationship between the consultation length and PNs use of MI techniques. However, the effects $(r=0.02)$ are very small (results of regression coefficients not shown).

\section{Differences between primary and secondary prevention consultations}

Table 3 presents the results of the multilevel analyses with MI techniques and consultation length as dependent variables and the two types of prevention consultations as independent variables.

These analyses reveal no significant differences between the two types of prevention consultations (model 1), even after correcting for sociodemographics, smoking, alcohol use and physical activity (model 2,3). None of the interaction terms added to model 3 were statistically significant (results of interaction analyses not shown). The regression coefficients are depicted in Table 3. The non-significant coefficients range was from -0.03 to -0.23 . Hence, differences between the groups are small. After adjustment for sociodemographics and self-reported current lifestyle behavior the coefficients hardly change. The unexplained variance on practice nurse level (highest level) ranged from 0.044 to 0.066 for Domain 1 (model 1, 3, 2), from 0.066 to 0.80 for Domain 2, from 0.052 to 0.086 for Domain 3 , from 0.081 to 0.138 for Domain 4, from 0.052 to 0.084 for BECCI mean sum score and from 30.02 to 32.62 for the consultation length. The intraclass correlation (ICC) on the four BECCI domains and BECCI mean sum score ranged from 0.10 to 0.15 for model 1 .

Our results show no significant association between the type of consultation and speaking time (odds ratio $=1.3 ; 95 \%$ $\mathrm{CI}=0.5$ - 3.7). The unexplained variance on practice nurse level ranged from 1.336 to 1.542 (model 1 and 2) for speaking time. The ICC on speaking time is 0.29 for model 1 .

\section{Discussion}

This study is, as far as we know, the first to examine whether and how PNs apply MI techniques in real-life primary care consultations and if they adjust their MI skills to the type of prevention consultation. PNs do appear to apply MI techniques, but only to a moderate level. This is in line with previous findings suggesting that MI skills are not easily applicable in daily practice. Heinrich [28] found a limited use of MI, Voogdt-Pruis [39] concluded that within cardiovascular prevention PNs should pay more attention to MI and Efraimsson and colleagues [40] demonstrated that nurses rarely used MI techniques in their smoking cessation communication with patients. In the present study, differences in the use of MI techniques may also be due to differences in the content and extensiveness of training in MI which all PNs went through.

As mentioned before, we found that PNs use MI techniques with substantial variation between the four domains. PNs demonstrate sensitivity to talking about other issues than behavior change, encourage the patient to talk about current behavior or status quo and are sensitive to the patients' concerns and understanding when providing information. In contrast, PNs particularly fail to meet the use of empathic statements when the patient talks about behavior change, often forget to summarize what the patient says, to ask patients about their willingness to talk about their behavior and do not always acknowledge the challenges of behavior change. Furthermore, although the majority of the PNs meet the required MI speaking time, in about one sixth of the consultations PNs talked more than half of the time.

No differences were found in the use of MI between primary and secondary prevention consultations. The gain to help patients in primary consultations by preventing complications may equal the necessity to help the disease from aggravating in secondary prevention, both requiring MI. If so, MI has relevance for primary and secondary consultations.

Our definition of primary and secondary prevention consultations is in line with previous studies [39, 41, 42]. In research on prevention, however, other definitions of primary and secondary prevention are also used. For example, Saxena, Jane-Llopis and Hosman [43] among others [44], distinguish primary, secondary and tertiary prevention in which secondary and tertiary prevention overlap with our primary and secondary prevention, respectively. To avoid ambiguity regarding the opposite or sometimes overlapping definitions of primary and secondary prevention, we plea for a more universal nomenclature.

\section{Strengths and limitations}

Our results are based on observational data instead of self-reported data only. Another major strength is that consecutive patients were approached and recruited during a regular visit to their PN and were not selected for any type of condition. Moreover, patients were not notified in advance about the study and when asked for participation in the waiting room, only $6 \%$ refused to participate. We thus got a realistic insight into the application of behavioral change techniques in usual daily practice.

There are also some limitations. First, the length of the MI training differed substantially between PNs. Post-hoc analysis did not reveal a positive influence of the length of the training. Our observations show a limited use of MI techniques. But, some BECCI-items are only completed when it is applicable within the context. MI focuses on resolving ambivalence between desired behavior and actual behavior and on enhancing intrinsic motivation to behavioral change. 
When medical parameters show normal levels or patient's lifestyle appears healthy, some MI techniques may be redundant. Furthermore, although there is evidence for the effectiveness of MI there are many other approaches to behavior change that show equally effective outcomes $[24,25]$. Besides, motivation is only one of a range of factors influencing behavior [24].

\section{Implications for future research and clinical practice}

In conformity with previous studies [28, 45, 46], our study suggests that training is not enough for acquiring MI skills. Teaching of MI techniques has been shown before to influence practitioner's behavior [30, 45, 47], but many practitioners tend to return to old counselling habits after a few months $[24,45,46]$. Though additional training might strengthen and maintain the new counseling skills, training needs to focus on enhancing new counseling behavior consistent with MI and suppressing old counseling behavior that is inconsistent with MI [28]. Furthermore, all members of a medical practice need to be motivated to change and to have a shared understanding of the meaning of an approach [46]. Besides, it is important that health care providers are supported by their supervisor [48] and colleagues [30, 34]. We suggest that health care providers, like PNs, who want to acquire MI skills follow an extensive training with sufficient follow-up. Besides continuing education, the training could be extended by video-feedback [31] and feedback based on participating observation.

Lastly, an explanation for the insufficient MI use may be that the PNs also have to (prove to) adhere to clinical guidelines at the same time $[39,49]$. It is possible that PNs find it hard to combine these guidelines with MI. Clinical practice guidelines demand PNs to meet certain task requirements, but PNs also want to take the patients' motivation into account as part of MI. This may be contradictory. Future research could investigate this hypothesis.

\section{Acknowledgement}

We would like to thank the patients and practice nurses for their participation. The study was funded by the Dutch Ministry of Health, Welfare and Sport.

\section{Conflict of Interest Statement}

No conflict of interest has been declared by the authors.

\section{References}

1. WHO (The World Health Organization). Innovative care for chronic conditions: Building blocks for action. Geneva, Switzerland: WHO, 2002. Retrieved from http:// www.who.int/diabetes/publications/iccc_exec_summary_eng.pdf

2. Coups EJ, Gaba A, Orleans CT. Physician screening for multiple behavioral health risk factors. Am J Prev Med. 2004;27(2 Suppl):34-41.

3. NICE (the National Institute for Health and Clinical Excellence). Four commonly used methods to increase physical activity: brief interventions in primary care, exercise referral schemes, pedometers and communitybased exercise programmes for walking and cycling, 2006. Retrieved from http://www.nice.org.uk/nicemedia/live/11373/31840/31840.pdf

4. Whitlock EP, Orleans CT, Pender N, Allan J. Evaluating primary care behavioral counseling interventions: an evidence-based approach. Am J Prev Med. 2002;22(4):267-284.

5. Cardol M, van Dijk L, de Jong J, de Bakker DH, Westert GP. Tweede Nationale Studie naar ziekten en verrichtingen in de huisartspraktijk. Huisartsenzorg: wat doet de poortwachter? (Second National Survey into diseases and actions in general practice. GP care: what does the gatekeeper?). Utrecht/Bilthoven: NIVEL/RIVM, 2004.

6. Soria R, Legido A, Escolano C, Lopez Yeste A, Montoya J. A randomised controlled trial of motivational interviewing for smoking cessation. Br J Gen Pract. 2006;56(531):768-774.

7. Katon W, Von Korff M, Lin E, Simon G. Rethinking practitioner roles in chronic illness: the specialist, primary care physician, and the practice nurse. Gen Hosp Psychiatry. 2001;23(3):138-144.

8. Laurant MGH. Changes in skill mix: The impact of adding nurses to the primary care team. $\mathrm{PhD}$ thesis. Nijmegen, The Netherlands: Radboud University Nijmegen, 2007.

9. Nielen MM, Assendelft WJ, Drenthen AJ, van den Hombergh P, van Dis I, Schellevis FG. Primary prevention of cardio-metabolic diseases in general practice: a Dutch survey of attitudes and working methods of general practitioners. Eur J Gen Pract. 2010;16(3):139-142.

10. Richards A, Carley J, Jenkins-Clarke S, Richards DA. Skill mix between nurses and doctors working in primary care-delegation or allocation: a review of the literature. Int J Nurs Stud. 2000;37(3):185-197.

11. Lamkaddem M, de Bakker D, Nijland A, de Haan J. De invloed van praktijkondersteuning op de werklast van huisartsen (The influence of practice support on the workload of GPs). Utrecht, The Netherlands: NIVEL/ University of Groningen, 2004.

12. Schmidt RA. Performance and learning a gross motor skill under conditions of artificially-induced fatigue. Res Q. 1969;40(1):185-190.

13. Richardson A, Cunliffe L. New horizons: the motives, 
diversity and future of 'nurse led' care. J Nurs Manag. 2003;11(2):80-84.

14. Barte JCM, ter Bogt NC, Beltman FW, van der Meer K, Bemelmans WJE. De GOAL-studie: een leefstijlinterventie voor patiënten met overgewicht en obesitas ter voorkoming van verdere gewichtsstijging (The GOAL study: a lifestyle intervention for overweight and obese patients to prevent further weight gain). Bijblijven. 2010; 26(6): 49-55.

15. ter Bogt NC, Bemelmans WJ, Beltman FW, Broer J, Smit AJ, van der Meer K. Preventing weight gain: oneyear results of a randomized lifestyle intervention. Am J Prev Med. 2009;37(4):270-277.

16. Lenz ER, Mundinger MO, Hopkins SC, Lin SX, Smolowitz JL. Diabetes care processes and outcomes in patients treated by nurse practitioners or physicians. Diabetes Educ. 2002;28(4):590-598.

17. Van Zuilen AD, Wetzels JF, Bots ML, Van Blankestijn PJ. MASTERPLAN: study of the role of nurse practitioners in a multifactorial intervention to reduce cardiovascular risk in chronic kidney disease patients. J Nephrol. 2008;21(3):261-267.

18. Bowen D, Ehret C, Pedersen M, Snetselaar L, Johnson M, Tinker L, Hollinger D, et al. Results of an adjunct dietary intervention program in the Women's Health Initiative. J Am Diet Assoc. 2002;102(11):1631-1637.

19. Hardcastle S, Taylor A, Bailey M, Castle R. A randomised controlled trial on the effectiveness of a primary health care based counselling intervention on physical activity, diet and CHD risk factors. Patient Educ Couns. 2008;70(1):31-39.

20. Richards A, Kattelmann KK, Ren C. Motivating 18- to 24-year-olds to increase their fruit and vegetable consumption. J Am Diet Assoc. 2006;106(9):1405-1411.

21. Martins RK, McNeil DW. Review of Motivational Interviewing in promoting health behaviors. Clin Psychol Rev. 2009;29(4):283-293.

22. Miller WR, Rollnick SR. Motivational Interviewing: preparing people for change. 2nd edition. New York, USA: The Guilford Press, 2002.

23. Rollnick S, Miller WR, Butler CC. Motivational Interviewing in Health Care: Helping Patients Change Behavior. New York, USA: The Guilford Press, 2008.

24. Greaves CJ, Sheppard KE, Abraham C, Hardeman W, Roden M, Evans PH, Schwarz P. Systematic review of reviews of intervention components associated with increased effectiveness in dietary and physical activity interventions. BMC Public Health. 2011;11:119.

25. van Achterberg T, Huisman-de Waal GG, Ketelaar NA, Oostendorp RA, Jacobs JE, Wollersheim HC. How to promote healthy behaviours in patients? An overview of evidence for behaviour change techniques. Health Promot Int. 2011;26(2):148-162.

26. Butler CC, Rollnick S, Cohen D, Bachmann M, Russell
I, Stott N. Motivational consulting versus brief advice for smokers in general practice: a randomized trial. British Journal of General Practice. 1999; 49: 611-616.

27. Koelewijn-van Loon MS, van der Weijden T, Ronda G, van Steenkiste B, Winkens B, Elwyn G, Grol R. Improving lifestyle and risk perception through patient involvement in nurse-led cardiovascular risk management: a cluster-randomized controlled trial in primary care. Prev Med. 2010;50(1-2):35-44.

28. Heinrich E. Diabetes self-management; strategies to support patients and health care professionals. PhD thesis. Maastricht, The Netherlands: Maastricht University, 2011.

29. Rubak S, Sandbaek A, Lauritzen T, Christensen B. Motivational interviewing: a systematic review and metaanalysis. Br J Gen Pract. 2005;55(513):305-312.

30. van Eijk-Hustings YJ, Daemen L, Schaper NC, Vrijhoef HJ. Implementation of Motivational Interviewing in a diabetes care management initiative in The Netherlands. Patient Educ Couns. 2011;84(1):10-15.

31. Noordman J, Verhaak P, van Dulmen S. Web-enabled video-feedback: a method to reflect on the communication skills of experienced physicians. Patient Educ Couns. 2011;82(3):335-340.

32. Lane $\mathrm{C}$. The Behaviour Change Counselling Index (BECCI), Manual for Coding Behaviour Change Counselling, 2002. Retrieved from http://motivationalinterview.net/library/BECCIManual.pdf

33. Lane C, Huws-Thomas M, Hood K, Rollnick S, Edwards K, Robling M. Measuring adaptations of motivational interviewing: the development and validation of the behavior change counseling index (BECCI). Patient Educ Couns. 2005;56(2):166-173.

34. Moran J, Bekker H, Latchford G. Everyday use of patient-centred, motivational techniques in routine consultations between doctors and patients with diabetes. Patient Educ Couns. 2008;73(2):224-231.

35. Spollen JJ, Thrush CR, Mui DV, Woods MB, Tariq SG, Hicks E. A randomized controlled trial of behavior change counseling education for medical students. Med Teach. 2010;32(4):e170-177.

36. Sim J, Wright CC. The kappa statistic in reliability studies: use, interpretation, and sample size requirements. Phys Ther. 2005;85(3):257-268.

37. Snijders TAB, Bosker RJ. Multilevel analysis. An introduction to basic and advanced multilevel modeling. First ed. London, England: Sage, 1999.

38. Goldstein H, Rabash J, Plewis I, Draper D, Brown WJ, Yang M, Woodhouse G, Healy M. A user's guide to MLwiN. London, England: Multilevel Models Project, Institute of Education, 1998.

39. Voogdt-Pruis HR. Cardiovascular prevention; nurses and doctors working together. PhD thesis. Maastricht, The Netherlands: Maastricht University, 2011. 
40. Efraimsson EO, Fossum B, Ehrenberg A, Larsson K, Klang B. Use of motivational interviewing in smoking cessation at nurse-led chronic obstructive pulmonary disease clinics. Journal of Advanced Nursing. 2011; 1-16.

41. Campbell NC, Ritchie LD, Thain J, Deans HG, Rawles JM, Squair JL. Secondary prevention in coronary heart disease: a randomised trial of nurse led clinics in primary care. Heart. 1998;80(5):447-452.

42. Lawton BA, Rose SB, Raina Elley C, Dowell AC, Fenton A, Moyes SA. Exercise on prescription for women aged 40-74 recruited through primary care: two year randomised controlled trial. Br J Sports Med. 2009;43(2):120-123.

43. Saxena S, Jane-Llopis E, Hosman C. Prevention of mental and behavioural disorders: implications for policy and practice. World Psychiatry. 2006;5(1):5-14.

44. Marinho S, Simpson A, Custovic A. Allergen avoidance in the secondary and tertiary prevention of allergic diseases: does it work? Prim Care Respir J. 2006;15(3):152-
158.

45. Miller WR, Mount KA. A small study of training in motivational interviewing: Does one workshop change clinician and client behavior? Behavioural and Cognitive Psychotherapy. 2001; 29: 457-471.

46. Towle A, Godolphin W, Grams G, Lamarre A. Putting informed and shared decision making into practice. Health Expect. 2006;9(4):321-332.

47. Madson MB, Loignon AC, Lane C. Training in motivational interviewing: a systematic review. J Subst Abuse Treat. 2009;36(1):101-109.

48. Van der Weijden, T. Richtlijnen in de spreekkamer, van dogma naar dans (Guidelines in the consulting room, from dogma to dance). Inaugural Lecture. Maastricht, The Netherlands: Maastricht University, 2010.

49. Gucciardi E, Fortugno M, Horodezny S, Lou W, Sidani S, Espin S, Webster F, et al. Will Mobile Diabetes Education Teams (MDETs) in primary care improve patient care processes and health outcomes? Study protocol for a randomized controlled trial. Trials. 2012;13(1):165. 